\title{
Model of trust in work groups
}

\author{
Andrey V. Sidorenkov, Irina I. Sidorenkova \\ Southern Federal University, Rostov-on-Don, Russia
}

\begin{abstract}
A multi-dimensional model of trust in a small group has been developed and approved. This model includes two dimensions: trust levels (interpersonal trust, micro-group trust, group trust, trust between subgroups, trust between subgroups and group) and types of trust (activity-coping, information-influential and confidentially-protective trust). Each level of trust is manifested in three types, so there are fifteen varieties of trust. Two corresponding questionnaires were developed for the study. 347 persons from 32 work groups participated in the research. It was determined that in a small group there is an asymmetry of trust levels within the group. In particular, micro-group trust is demonstrated the most in comparison with other trust levels. There is also an asymmetry in the manifestation of interpersonal trust in a group structure. This is demonstrated by the fact that in informal subgroups, in comparison with a group as a whole, interpersonal confidential and performance trust is the most manifested. In a small group and in informal subgroups there are relationships between trust levels which have certain regularities.
\end{abstract}

Keywords: small group, informal subgroup, trust, trust levels, types of trust.

Over the past two decades, interest in the problem of organizational trust has significantly increased in industrialized countries (Kramer \& Tyler, 1996; Mayer et al., 1995; McAllister, 1995; Schindler \& Thomas, 1993). The growing interest in trust is explained by the fact that it is treated as a social capital that influences the economic effectiveness of organizational performance. In other words, trust can assist in information exchange, decrease control and management costs, and favor the development of inter- and intra-organizational relations, etc. (Shaw, 2000; Dirks, 2000; Zand, 1972).

Some authors review studies on trust based on different levels of analysis, including individual trust, team trust, organizational trust, and interfirm trust (Fulmer \& Gelfand, 2012). Special attention is paid to trust in work groups and teams due to their predominance in organizations and importance for their members. Trust in a group affects group effectiveness (Aubert \& Kelsey, 2003; Jarvenpaa et al., 1998; Webber, 2008), group development (Cohen et al., 1980), cooperative behavior and cohesion (Baron et al., 2003), willingness to exchange resources (Dirks \& Skarlicki, 2004), execution of instructions by employees and the efficiency of their work (Dirks, 2000), and adaptation of newcomers in a group (Moreland \& Levine, 2002), etc. 
However, there are several important aspects which have not been comprehensively covered in research works. First, there is no common viewpoint on the nature of trust, which due to the complicated nature of such a phenomenon. If we generalize the existing definitions, it is possible to single out several aspects of trust manifestation: (a) trust is a conviction in sincerity, honesty, decency, (b) trust is a reliance on current opinion or somebody's authority, and (c) trust is a conviction in other person's responsibility, and an expectation of actions that conform to generally accepted work standards. It is common for many definitions to recognize the following properties of trust: trust arises in situations that are characterized by uncertainty and risk; trust is connected with expectation of a certain result; trust is situationally and personally specific. In the simplified treatment, trust is understood as the general affective state (Pescosolido, 2003). However, there are two components in trust: cognitive and affective (McAllister, 1995; Webber, 2008). Cognitive-based trust is formed on the basis of actual knowledge, which the truster has about the trustee, while affective trust consists of emotional relations between people. Thus, there is a necessity to create such a conceptual framework that would allow different aspects of trust manifestation to be comprised.

Second, the attention of the authors is focused primarily on interpersonal trust in a dyad or a group as a whole. For example, the study of the trust of fullfledged members of work groups to quasi-members (Moreland \& Levine, 2002), trust of subordinates to a superior (Dirks, 2000), and the role of interpersonal trust in effectiveness of virtual orders (Aubert \& Kelsey, 2003). At the same time, the peculiarities of interpersonal trust in psychological group structure, that is in informal subgroups, between representatives of different informal subgroups in a group, etc. are not taken into consideration. Trust between an individual and a small group, between an individual and an informal subgroup, and between informal subgroups in a group, is not actually investigated. It should be noted that informal subgroups are formed in small groups of different types - in formal small groups (e.g., production groups, project teams, sport teams, the families consisting of three or more persons) and informal small groups (the company of friends on rest). For example, in work groups and groups of office workers of 5-15 persons, the number of informal subgroups varies from one to four (Sidorenkov, 2004, 2010). In such groups informal dyads and triads are met much more often, and ones consisting of 5 persons are met very seldom. On average, more than half of group members are included in informal subgroups. That is why ignoring informal subgroups does not allow a complete picture of specific features of trust in a group to be seen. In our research we are focused on informal subgroups within formal small groups. However, the offered model of trust can extend to informal small groups.

\section{Multi-dimensional model of trust manifestation in a group}

On the basis of the micro-group theory (Sidorenkov, 2006, 2010) a multidimensional model of trust in a small group has been developed, and it includes two dimensions: levels and types of trust manifestation. In the most general terms trust is understood as selective relationship of one subject (individual, subgroup, group) to 
another, based on evaluation of some characteristics of the other and readiness to interact with him in a certain way, and on a feeling of personal safety (well-being) as a result of this interaction.

\section{Levels of trust in a group}

A small group, as a system, has three structural levels of group activity: individual, subgroup, group. Each of them acts as a subject that performs certain functions in relation to the others, and is also immanently more widely presented. In spite of the hierarchy of the levels, they are not in strict collateral subordination and they are dynamic in their interaction, depending on the internal and external conditions of the life activity of the group.

In a small group there can be intralevel relations (individual — individual, subgroup - subgroup) and interlevel relations (individual — group, individual — subgroup, subgroup - group) (Figure 1).

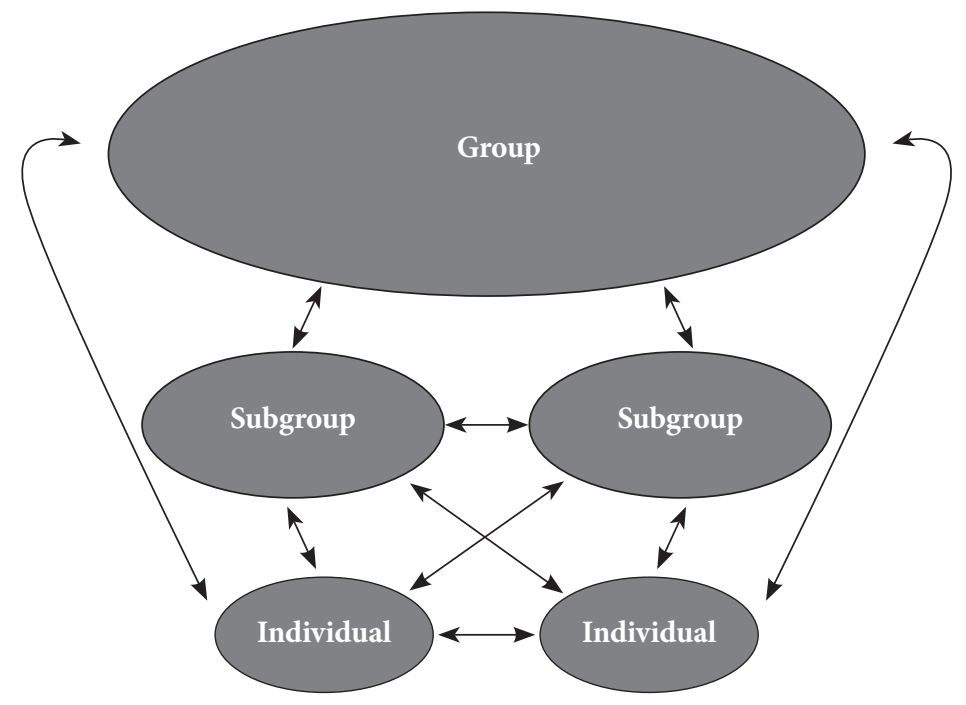

Figure 1. Intra- and interlevel relations in a small group

Therefore it is possible to allocate five levels of trust in a small group:

- interpersonal (IT): trust between individuals within informal groups, between representatives of different informal subgroups, between representatives of subgroups and members not included in subgroups, and between members not included in subgroups;

- micro-group (MGT): trust of individuals to an informal subgroup and trust of a subgroup to separate individuals;

- $\operatorname{group}(G T)$ : trust of individuals to a group and trust of a group to separate individuals;

- between a subgroups (SST): trust between informal subgroups, between subgroups and members not included in them;

- between a subgroup and a group (SGT): trust of an informal subgroup to a group and trust of a group to a subgroup. 


\section{Types of trust in a group}

There are three major fields of social activity of an individual, a subgroup and a group: performance, communication, and moral actions. In each field of activity a type of trust corresponding to it is manifested: activity-coping, information-influential, and confidentially-protective trust. Each type of trust includes three components: cognitive (conviction of a subject in presence - absence of certain characteristics, inherent in the object of trust), affective (positive - negative evaluation of the object of trust), behavioral (readiness of a subject to interact with an object of trust in a certain way). Activity-coping trust (ACT) is based on a positive-negative evaluation of knowledge and skills of another individual (subgroup, group) and represents a conviction in its ability to efficiently perform an activity or to contribute to the common cause, as well as a readiness to cooperate with it. Such trust is determined by the competence and responsibility of another subject in the process in doing certain work. In respect of this trust, the following utterances are typical: ' $\mathrm{I}$ am sure he (she) will do the job the way it should be done', 'I am sure that the group/ subgroup will be able to join efforts and complete the set task'. Information-influential trust (IIT ) is based on a positive-negative individual estimation of a viewpoint of another object, and it represents confidence in the rightness of his/her opinion, as well as a readiness to perceive information and to be influenced by him/her. Such trust is determined by the competence of another individual (subgroup, group) in respect of questions which are indefinite and significant for the one who trusts. The following utterances are typical for such a type of trust: 'I am sure he (she) can size up the situation comprehensively and take the correct decision', 'I am sure that the group/subgroup is thinking in the right direction'. Confidentially-protective trust (CPT) is based on positive-negative individuals' estimation of the moral portrait of another object, and it represents confidence in his (her) decency, as well as readiness to be open with him (her) and to rely on him (her) on the basis of the feeling of personal safety. For such a type of trust the following utterances are typical: 'I could tell him (her) my secret thoughts and be sure that he (she) will not betray me', 'I am sure that the group/subgroup will support me if anything threatens me'. So as fields of social activity (performance, communication, moral actions) are often presented in these or those reality situations, types of trust are interconnected.

\section{Levels and types of trust in a group}

Two dimensions of trust are integrated with each other, so each level of trust is manifested in three types. Thus, there are fifteen varieties of trust: interpersonal performance trust, interpersonal information trust, interpersonal confidential trust, etc. For example, interpersonal confidentially-protective trust is based on an individual's estimation of the moral portrait of another object, and it represents confidence in his/her decency, the individual's readiness to be open with another individual and to rely on him/her on the basis of the feeling of personal safety. Group activity-coping trust is based on an individual's estimation of the possibilities of team work of all members of the group, and represents confidence in the group's ability to successfully solve problems, as well the individual's readiness to participate in team work with members of the group. 
Thus, the purpose of this research is to study the levels and types of trust in work groups, including the socio-psychological structure of the groups (informal subgroups and outside members, relations between them). We put forward the following hypotheses:

Hypothesis 1a: Different levels of trust have, in comparison with one another, different degrees of manifestation within a group as a whole, and within informal subgroups.

Hypothesis 1b: Types of trust can have a different degrees of expressiveness at a given level of trust. Types of interpersonal trust are more strongly manifested within informal subgroups than in a small group as a whole.

Hypothesis 2a: In a small group and informal subgroups there is a straight or feedback relationship between levels of trust, which is displayed in a positive or negative correlation.

Hypothesis $2 b$ : In a small group and informal subgroups there are certain connections between types of trust that are displayed in positive correlation; the quantity of these relationships depends on level of trust.

In this research the trust of individuals to other individuals, subgroups and the group, and also trust between subgroups, and between subgroups and the group as a whole, was studied. In it the mutual trust between individuals, between individuals and subgroups, and between individuals and the group, was not considered.

\section{Method}

\section{Participants}

347 employees from 32 groups participated in the research. The groups varied in age and sex composition. The age of the subjects was within the range of 18 to 57 years. Both male and female groups were examined, and also groups with different ratios of males to females (there were $59.8 \%$ females and $40.2 \%$ males). These groups are small businesses or primary structural units in various organizations involved in motor vehicles (3 groups) and catering (2) service, trading in (7) and sales of real estate (2), fire-fighting (4) and military (2) units, hospitals (2), etc. The strength of the groups varied from 6 to 24 persons (groups consisting of 8-12 persons predominated). The average size of group was 9.1 members. All groups were organizationally and psychologically established. These small groups had been in existence for at least one year.

\section{Measures}

Informal subgroups. To single out in groups informal subgroups and members not included in them, a formalized algorithm, developed by Gorbatenko (1984) is used. A sociometric poll of the group members is conducted to the non-specific criterion: 'Select the group members, with whom you maintain the closest relations'. A non-parametric procedure is used. This algorithm consists of the following actions: (a) compilation of the 'description' matrix to characterize the concrete status of the grouped variables, (b) determination of the numerical value of the links (similarity) among the grouped members, and construction of a similarity factors ma- 
trix, (c) arrangement of individuals into subgroups and identification of the index, which characterizes the quality of these subgroups, and (d) selection of the 'densest' subgroups. On the basis of comparison between the formalized algorithm data and the experts' assessments, it was found that the empirical indices of the algorithm accuracy (by quantity and composition of the subgroups) in different groups vary from 78 to $100 \%$.

The method identifying informal subgroups and outside members is tied with the questionnaires (QIT and QGMT).

Interpersonal trust. Questionnaire of Interpersonal Trust in Groups and subgroups (QIT) was developed (Sidorenkov \& Sidorenkova, 2007). Study of the degree of characteristics, shown in points is carried out on a 7-point scale basis (from completely agree (1) to completely disagree (7)). QIT includes three sub-scales for the estimation of three types of interpersonal trust (IT) - activity-coping (ACT), information-influential (IIT), and confidentially-protective (CPT) trust. Each type of trust includes three components: cognitive, affective, and behavioral. These trust components were considered for the selection of the questionnaire items. The Questionnaire consists of 12 items (with a reverse formulation) -4 for each subscale ('I avoid straight talks' (CPT), 'I can not rely on the opinion of others in respect to disputable points' (IIT), 'Sometimes I doubt that others do the job the way it should be done' (ACT). QIT consists of two parts: 'Among those with whom I maintain close relations' and 'In the group as a whole. The first part allows the study of interpersonal trust in informal subgroups, and the other - in a small group as a whole. The complete examination variant makes it possible to obtain three indices of interpersonal trust: ACT-G-I, IIT-G-I and CPT-G-I, and three indices of trust inside the subgroups: ACT-S-I, IIT-S-I, CPT-S-I. Test measurements by subscales may vary from 4 to 28 . The higher the numerical value of subscales, the stronger this or that type of trust is manifested.

The Cronbach's alpha values for the subscales were ACT-G-I (.78) and ACT-S-I (.79), IIT-G-I (.69) and IIT-S-I (.71), CPT-G-I (.77) and CPT-G-I (.76). Test-retest correlations for subscales were .72 (ACT), .77 (IIT), and .75 (CPT).

Group and micro-group trust. Questionnaire of Group and Micro-group Trust in a Group and a subgroup (QGMT) is developed according to the same scheme as in the previous Questionnaire. It also includes three subscales, but for the study of three types (ACT, IIT, CPT) of group (GT) and micro-group (MGT) trust. (Group / microgroup trust is trust of the members to the group / informal subgroups.) QGMT consists of 12 items (with a reverse formulation) - 4 for each subscale. Each type of trust includes three components: cognitive, affective, and behavioral. The Questionnaire consists of two parts: 'Those with whom I maintain close relations' and 'Group as a whole. The first part is dedicated to studying micro-group trust, the other - to studying group trust. Examinations can be carried out in the complete or in the concise variant. The first option allows the determination of three group trust indices (ACT-G, IIT-G, CPT-G) and three microgroup trust indices (ACT-MG, IIT-MG, CPT-MG), while the second option yields only three group trust indices (ACT-G, IIT-G, CPT-G). Test measurements by subscales may vary from 4 to 28 .

The Cronbach's alpha values for the subscales were .81 (ACT-G) and .71 (ACTMG), .75 (IIT-G) and .76 (IIT-G-MG), .79 (CPT-G) and .74 (CPT-MG). The cor- 
relation coefficients between two tests (test-retest reliability) for subscales were .69 (PT-G), .78 (InfT-G), and .83 (CT-G).

Trust between subgroups. To evaluate trust between subgroups, a relative index is used. It is calculated from correlation of the data, obtained from two parts of the QIT. That is: in each sub-scale, the index in 'In the group as a whole' is divided by the index in 'Among those with whom I maintain close relations', and then is multiplied by the constant 10 . Numerical values may vary from 1.4 to 70 , but often they are in the interval from 5 to 10 . For example, the closer the index is to 10 , the less is the difference between interpersonal trust in a group on the whole and in informal subgroups. In this case it is possible to say that there are trust relationships between informal subgroups.

Trust of subgroups to a group. It is also determined implicitly, but on the basis of correlation of indexes of two parts of QGMT. In each sub-scale, the index of the part 'Group as a whole' is divided by the index of the part 'Those with whom I maintain close relations' and is multiplied by the constant 10 .

\section{Procedure}

Both questionaries are included in the computer technology Integrated Social-psychological Diagnostics of a Group (ISPDG), and they are integrated with a formalized method of depicting informal subgroups and members not included in them (Sidorenkov \& Pavlenko, 2007).

The research was computerized, applying ISPDG, which allows: (a) to ensure consistency of research conditions due to the permanence of the implemented program, (b) to automatically control the work of the research participants, as well as to block the research and to warn in case of skipping some tasks or misrepresentation of answers, and (c) to automatically process the results, etc. The functional capabilities of the software drastically raise the validity of the results obtained through the computer format of examination, as compared with the paper format.

\section{Results}

\section{Informal subgroups in a group}

In all tested groups, informal subgroups were detected. The number of subgroups in groups varies from two to four (except for two groups, each of which has only one subgroup). On average, more than half of group members (60,4\% individuals) were included in subgroups. In different groups, the number of persons included in subgroups varies from 28 to $97 \%$. Dyads (52.2\% of subgroups) predominate in groups, and triads (32.4\%) are also often found. subgroups consisting of four persons $(12.6 \%)$ are formed much more seldom, and subgroups consisting of five $(1.9 \%)$ and six $(0.9 \%)$ persons appear very seldom.

The obtained results give grounds to investigate: (a) interpersonal trust not only in a group on the whole, but in informal subgroups, and between representatives of different subgroups, etc. and (b) micro-group and group trust, trust between subgroups and trust between subgroups and a group. 


\section{Manifestation of levels and types of trust}

The results (Table 1) will be considered separately by interpersonal trust, microgroup trust, group trust and trust between subgroups, trust of subgroups to a group, because to estimate the manifestation degree of the first three levels absolute indexes are used, and to estimate the other two levels - relative indexes are used, which makes it impossible to compare them.

Table 1. Levels and types of trust in a small group (average score)

\begin{tabular}{cccccc}
\hline $\begin{array}{c}\text { Types } \\
\text { of trust }\end{array}$ & IT & GT & MGT & SST & SGT \\
\hline \multirow{2}{*}{ ACT } & $13.6(18.5 / 13.1)$ & $17.0(17.3 / 16.8)$ & $20.4(20.9 / 19.5)$ & 7.4 & 8.3 \\
IIT & $12.5(15.6 / 12.3)$ & $17.3(17.1 / 17.4)$ & $20.3(20.8 / 19.6)$ & 8.2 & 8.5 \\
CPT & $11.3(18.7 / 11.0)$ & $17.4(17.2 / 17.6)$ & $20.8(21.3 / 20.4)$ & 6.4 & 8.3 \\
\hline
\end{tabular}

Note: The figure before round parenthesis is an index of trust in a group as a whole, and the figure in parenthesis is an index of trust in members of informal subgroups (before parenthesis) and members not included in informal subgroups (after parenthesis).

First, we should analyze the degree of trust manifestation levels taking into consideration each type (H1a). In a group as a whole, individual's trust to subgroups (MGT) is manifested the most, trust to group (GT) is less manifested, and interpersonal trust (IT) is the least manifested. All differences between mean values are statistically significant $(p<.001)$ for each type of trust: ACT, IIT, CPT. In a totalgroup context, no difference was discovered between members of informal subgroups and members not included in subgroups by the degree of demonstration of trust level manifestation. In informal subgroups there is another tendency: by each type, MGT is the most manifested, IT is less manifested, and GT is the least manifested. IIT is an exception which, on the contrary, is less manifested at the level of interpersonal trust in comparison with trust to a group. Statistically significant differences were revealed between all levels of trust manifestation ( $p<.001$ и $p<.01)$.

If we draw attention to the other two levels, trust of subgroups to a group (SGT) in a group as a whole is manifested more strongly than trust between subgroups (SST). A statistically significant difference between mean values is present in such types of trust as ACT and CPT $(p<.001)$.

Second, conversely, we compare indexes of trust types by each level of their manifestation (H1b). Significant differences of mean values were determined:

1) at the interpersonal trust level:

- in informal subgroups between CPT and IIT $(p<.001)$, between IIT and $\operatorname{ACT}(p<.001)$;

- of members of subgroups with representatives of other subgroups and members not included in subgroups between CPT and IIT $(p<.01)$, between IIT and ACT $(p<.01)$;

- of members not included in subgroups between CPT and IIT ( $p<.01)$, between CPT and ACT $(p<.001)$;

2 ) at the level of trust between subgroups: between CPT and IIT $(p<.001)$, between CPT and ACT $(p<.01)$, between CPT and ACT $(p<.01)$. 


\section{Relationship between levels and between types of trust}

Let's study relationships between levels of trust manifestation (H2a) separately, by each type (Table 2). I

$\mathrm{n}$ a small group as a whole, a statistically significant relationship between the following levels is detected: interpersonal trust and trust between informal subgroups (direct relationships by CPT and ACT types); micro-group trust and trust between subgroups (feed-back by IIT type); microgroup trust and trust of subgroups to a group (feed-back by IIT type); group trust and trust between subgroups (direct relationship by PT type); group trust and trust of subgroups to a group (direct relationship by ACT, IIT and CPT types); trust between subgroups and trust of subgroups to a group (direct relationship by ACT type).

In informal subgroups there is a statistically direct relationship between interpersonal trust and micro-group trust (ACT, IIT, CPT), and between micro-group trust and group trust (IIT, CPT). Besides, in the first case the relationship is closer than in the second. There is no relationship between interpersonal and group trust, just as in a group as a whole.

Let's refer to relationships between types of trust $(\mathrm{H} 2 \mathrm{~b})$ separately by each level (Table 3). There is a certain sequence of growing correlation between ACT, IIT, and CPT from level to level. That is: the weakest relationship is at the level of interpersonal trust, a closer relationship is at the level of micro-group trust, and the strongest relationship is at the level of group trust.

Table 2. Correlation between trust levels (separately by type)

\begin{tabular}{|c|c|c|c|c|c|}
\hline \multirow{2}{*}{\multicolumn{2}{|c|}{$\begin{array}{c}\text { Types and } \\
\text { Levels of trust }\end{array}$}} & \multicolumn{4}{|c|}{ Trust levels } \\
\hline & & MGT & GT & SST & SGT \\
\hline \multirow{5}{*}{ U } & IT & $.23\left(.51^{\star}\right)$ & $.25(.18)$ & $.71^{*}$ & -.13 \\
\hline & MGT & 1 & $.28\left(.38^{\star *}\right)$ & .05 & .08 \\
\hline & GT & - & 1 & .26 & $.69^{\star *}$ \\
\hline & SST & - & - & 1 & .32 \\
\hline & SGT & - & - & - & 1 \\
\hline \multirow{5}{*}{ 旨 } & IT & $.01\left(.35^{\star \star}\right)$ & $.03(.14)$ & .34 & .07 \\
\hline & MGT & 1 & $.11\left(.36^{* *}\right)$ & $-.56^{\star *}$ & $-.61^{\star \star}$ \\
\hline & GT & - & 1 & .09 & $.59^{\star *}$ \\
\hline & SST & - & - & 1 & .41 \\
\hline & SGT & - & - & - & 1 \\
\hline \multirow{5}{*}{ 㫐 } & IT & $0\left(.46^{* *}\right)$ & $.31(.23)$ & $.59^{* *}$ & .24 \\
\hline & MGT & 1 & $.19(.27)$ & .01 & -.27 \\
\hline & GT & - & 1 & $.77^{\star}$ & $.74^{\star}$ \\
\hline & SST & - & - & 1 & $.76^{\star}$ \\
\hline & SGT & - & - & - & 1 \\
\hline
\end{tabular}

Note: The figure before parenthesis is a correlation of indexes of the group as a whole, and the figure in parenthesis is a correlation among members of informal subgroups. ${ }^{*} \mathrm{p}<.001,{ }^{* *} \mathrm{p}<.05$. 
Table 3. Coefficients of correlation between types of trust (separately by each level)

\begin{tabular}{|c|c|c|c|c|c|c|c|c|c|}
\hline \multirow{3}{*}{$\begin{array}{c}\text { Types of } \\
\text { trust }\end{array}$} & \multicolumn{9}{|c|}{ Levels and Types of trust } \\
\hline & \multicolumn{3}{|c|}{ IT } & \multicolumn{3}{|c|}{ MGT } & \multicolumn{3}{|c|}{ GT } \\
\hline & CPT & IIT & ACT & $\mathrm{CPT}$ & IIT & ACT & CPT & IIT & ACT \\
\hline $\mathrm{CPT}$ & 1 & $.43^{* * *}$ & $.55^{\star * *}$ & 1 & $.71^{\star}$ & $.64^{* *}$ & 1 & $.77^{\star}$ & $.73^{\star}$ \\
\hline IIT & - & 1 & $.67^{\star *}$ & - & 1 & $.75^{\star}$ & - & 1 & $.81^{\star}$ \\
\hline ACT & - & - & 1 & - & - & 1 & - & - & 1 \\
\hline
\end{tabular}

Note: ${ }^{\star} \mathrm{p}<.001,{ }^{* *} \mathrm{p}<.01,{ }^{* *} \mathrm{p}<.05$.

\section{Discussion}

1. A different degree of manifestation of trust levels in a group as a whole and within informal subgroups allows us to speak of a phenomenon of asymmetry of trust levels in a group (H1a). Predominance of micro-group trust over group trust is explained by the fact that a subgroup is considered by individuals to be a more integral unit, with an ability to more effectively realize functions in relation to its members, than a group as a whole.

Domination (in a group as a whole) of group trust over interpersonal trust plays a compensational role in case of a decrease in the latter, thus supporting the psychological integrity of a group as a whole. A higher degree of manifestation of micro-group trust in comparison with other levels in an informal subgroup ensures psychological integrity and relative stability of a subgroup, and its behavior as a collective unit.

Predominance of trust of subgroups to a group over trust between subgroups by CPT type, is possibly connected with the fact that: (a) a group, in comparison with some subgroups, is perceived as a higher unit, which is in some way able to protect the interests of group members in the external environment and (b) some other subgroups are considered to be a potential threat source inside a group. Similar correlation of these levels of trust by ACT type is explained by the fact, on the one hand, that a group has greater resources than some separate subgroups, and on the other, that there is a competition between separate subgroups. A lack of difference between these levels by IIT type is explained by the fact that knowing the opinion of other subgroups in respect of some important issues is no less important than knowing the opinion of a group, especially if we speak about the development of relations between subgroups.

Interpersonal trust by all types is much more strongly manifested in subgroups, than in a group as a whole, that is indicative of the phenomenon of asymmetry of interpersonal trust manifestation in a group structure ( $\mathrm{H} 1 \mathrm{~b})$. This can be explained in the following way: (a) members of a subgroup have characteristics which are more similar and generally significant in comparison with other group members, (b) the strength of relations and intensity of interaction in subgroups is much higher than in a group as a whole, and (c) one of factors of sub-grouping individuals is trust in each other. Besides, in subgroups interpersonal CPT and ACT are more strongly manifested, and interpersonal IIT is more weakly manifested. Predominance of the 
first type of trust can be explained by the fact that it is crucial to ensure a feeling of personal safety, which is more successfully realized in a subgroup than in the context of a group as a whole. This is even more evident when there is an aggressive environment in a group and people have a fear of staying alone. Predominance of $\mathrm{CPT}$ is connected with the fact that in subgroups, in comparison with a group as a whole, people can rely on responsibility and assistance of others to a greater extent, and that means they can perform their main work more successfully.

2. There is a certain relationship between levels of trust in a group $(\mathrm{H} 2 \mathrm{a})$, which in general can be described as follows: (a) in informal subgroups and by cumulation of members not included in them, there is a connection between levels of trust that are hierarchically close to each other: IT-MGT-GT, (b) in a group as a whole trust between subgroups is a binding level between all the rest, and (c) an increase or decrease of one level of trust causes correspondent or opposite manifestation of another level.

Relationship between interpersonal trust and trust of individuals to a subgroup. When a subgroup is successful in maintaining its position in a group or it demonstrates a high work productiveness, this leads to an increase of members' trust to their subgroup, and further, to a strengthening of interpersonal trust to it. If interpersonal mistrust is growing in a subgroup, this may lead to trust to a subgroup decreasing.

Relationship between individuals' trust to subgroups and to a group. If a group can stand up for its opinion, defend its interests, or show high results of work in an organization, this gives assurance to members of subgroups in the possibilities of not only the group as a whole, but of their subgroups too.

Trust relationship between subgroups, on the one hand, and trust relationship of individuals to a group and subgroups to a group, on the other. When suspicion between subgroups is growing in a group, this results in a decrease of trust to the group. Growth of trust to a group, in its turn, can, but not so evidently, result in a strengthening of trust between subgroups.

Trust relationship between subgroups, on the one hand, and trust relationship of individuals to a subgroup, on the other hand. In case of a progression of conflict and mistrust between subgroups, trust of members to their subgroups will grow. However, if a subgroup is ineffective in the process of interaction with other subgroups, trust of its members will be decreased, and trust to some other subgroups or a group on the whole may increase.

A different degree of manifestation and a certain sequence of growing correlation between trust types (H2b) from level to level is indicative of a different degree of their presence in the minds of individuals. That is: a stronger differentiation of trust types is observed at the level of interpersonal relations (low correlation), a lower one at the level of relation to subgroups (intermediate correlation), and the least one at the level of relation to a group (highest correlation). This regularity is explained by the fact that in the minds of individuals, a subgroup, and, especially, a group is presented in more generalized characteristics, than separate individuals are.

In addition we would like to note, that in a group as a whole there is a very weak or weak correlation, and between types at this or that level there is a middle or high correlation. A higher correlation between types of trust is explained by the fact that we speak about types of one and the same phenomenon at one and the same level of its manifestation. 


\section{Future research}

Several prospects for further studies are possible. First, it's necessary to examine forms of manifestation of trust levels in a group. For example, interpersonal trust may be personified and depersonified. Personified trust is specified by the individual characteristics of group members. Depresonified trust is impersonal trust that is meditated by (a) micro-group trust; (b) trust between subgroups; and c) group trust.

Secondly, it is necessary to study the characteristics of a subject and an object of trust, which directly affect trust between them. The matter of man's particularities which influence his/her trust and trust to him/her, has been more or less investigated. At the same time, the characteristics of a subgroup or a group as a subject or an object of trust have not been substantially investigated.

Thirdly, in the research particular characteristics of trust of individuals to a subgroup and a group have been examined. In contrast, it is no less important to investigate the trust of a subgroup and a group to an individual.

Fourthly, another important question is the following: what level and what type of trust has the most significant impact on group effectiveness.

\section{References}

Aubert, B.A., \& Kelsey, B.L. (2003). Further understanding of trust and performance in virtual teams. Small Group Research, 34, 575-618. doi: 10.1177/1046496403256011

Baron, R., Kerr, N., \& Miller, N. (2003). Socialnaya psikhologiya grupp: processy, resheniya, deystviya [Social psychology of group: processes, solutions, action]. St-Petersburg: Piter.

Dirks, K.T. (2000). Trust in Leadership and Team Performance: Evidence From NCAA Basketball. Journal of Applied Psychology, 12, 1004-1012. doi: 10.1037/0021-9010.85.6.1004

Dirks, K.T., \& Skarlicki, D.P. (2004). Trust in leaders: Existing research and emerging issues. In R.M. Kramer \& K.S. Cook (Eds.). Trust and distrust in organizations: Dilemmas and approaches (pp. 21-40). NY: Russell Sage Foundation.

Fulmer, C.A., \& Gelfand, M.J. (2012). At What Level (and in Whom) We Trust: Trust Across Multiple Organizational Levels. Journal of Management, 38, 1167-1230. doi: 10.1177/ 0149206312439327

Gorbatenko, A.S, (1984). Metodika opredeleniya struktury maloj gruppy s pomochiu formalizovannogo analiza mejlichnostnyh vyborov [Method of definition of structure of small group by means of the formalized analysis of interpersonal elections]. Voprosy Psychologii [Issues of psychology], 4, 112-118.

Hill, C.L. (1990). Cooperation, opportunism, and the invisible hand: Implications for transaction cost theory. Academy of Management Review, 15, 500-514.

Jarvenpaa, S.L., Knoll, K. \& Leidner, D.E. (1998). Is anybody out there? Antecedents of trust in global virtual teams. Journal of Management Information Systems, 14, 29-65.

Kramer, R.M. (1999). Trust and distrust in organizations: Emerging perspectives, enduring questions. Annual Review of Psychology, 50, 569-598. doi: 10.1146/annurev.psych.50.1.569

Kramer, R.M., \& Tyler, T.R. (1996). Trust in organizations: Frontiers of theory and research. Thousand Oaks, CA: Sage.

Lewicki, R.J., \& Bunker, B.B. (1996). Developing and Maintaining Trust in Work Relationships. In R.M. Kramer \& T.R. Tyler (Eds.). Trust in Organisations (pp. 119-124). Thousand Oaks, CA: Sage. 
Mayer, R.C., Davis, J.H., \& Schoorman, F.D. (1995). An integrative model of organizational trust. Academy of Management Review, 20, 709-734.

McAllister, D.J. (1995). Affect- and cognition-based trust as foundations for interpersonal cooperation in organizations. Academy of Management Journal, 38, 24-59. doi: 10.2307/256727

Moreland, R.L., \& Levine, J.M. (2002). Socialization and Trust in Work Groups. Processes \& Intergroup Relations, 5(3), 185-201. doi: 10.1177/1368430202005003001

Pescosolido, A.T. (2003). Group Efficacy and Group Effectiveness: The Effects of Group Efficacy Over Time on Group Performance and Development. Small Group Research, 34, 20-42. doi: $10.1177 / 1046496402239576$

Rousseau, D.M., Sitkin, S.B., Burt, R.S., \& Camerer, C. (1988). Not So Different After All: A Cross-Discipline View of Trust. Academy of Management Review, 7, 393-404.

Schindler, P.L., \& Thomas, C.C. (1993). The structure of Interpersonal Trust in the Workplace. Psychological Reports, 10, 563-573. doi: 10.2466/pr0.1993.73.2.563

Shaw, R.B. (2000). Kluchi $k$ doveriu $v$ organizacii: rezultativnost, poraydochnost, proayvlenie zaboty [Keys to trust in the organization: Productivity, decency, display of care]. Moscow: Delo.

Shockley-Zalabak, P., Ellis, K., \& Winograd, G. (2000). Organizational trust: What it means, why it matters. Organization Development Journal, 18, 35-48.

Sidorenkov A.V. (2006). Mikrogruppovaya teoriya [Microgroup theory]. Rosskij Psichologicheskij Zhurnal [Russian Psychological Journal], 3, 18-36.

Sidorenkov A.V. (2010). Malay gruppa i neformalnye podgruppy: Mikrogruppovay teoriay. [Small group and informal subgroups: The microgroup theory]. Rostov-on-Don, Russia: SFU.

Sidorenkov A.V., Pavlenko R.V. (2007). Komputernaay tehnoloiay «Komplexnaay socialno-psihologicheskaay diagnostika gruppy» [Computer technique «Integrated Social and Psychological Diagnostics of a Group» (ISPDG)]. Svidetelstvo o oficialnoj registracii programmy dlay IBM No.2007611931 Federalnoj slujby po intellektualnoj sobstvennosti, patentam i tovarnym znakam [Certificate of official registration of a computer program No.2007611931 Federal Service for Intellectual Property, Patents and Trademarks of the Russian Federation]. Moscow.

Sidorenkov, A.V., \& Sidorenkova, I.I. (2007). Metodiki izucheniay doverij v maloj gruppe: metodicheskie rekomendacii [Questionnaires of trust in small group: The methodical recommendations]. Rostov-on-Don, Russia: SFU.

Webber, S.S. (2008). Development of cognitive and affective trust in teams: A longitudinal study. Small Group Research, 39, 746-769. doi: 10.1177/1046496408323569

Zand, D.E. (1972). Trust and managerial problem solving. Administrative Science Quarterly, 17(2), 229-239. doi: 10.2307/2393957 